\title{
Improving Nursing Education in Sri Lanka to take on New Challenges faced by Global Healthcare Systems
}

\author{
W. G. C. Kumara ${ }^{1} \&$ W. S. Sudusinghe ${ }^{2}$ \\ 1 Department of Nursing and Midwifery, General Sir John Kotelawala Defence University \\ 2 Department of Languages, General Sir John Kotelawala Defence University
}

ABSTRACT
This article discusses some novel approaches that can be implemented
in Sri Lanka to upgrade its nursing education to meet global
challenges. Globally, employers look for nursing professionals who
possess competencies compatible with the new demands of the
global healthcare system. Therefore, it has become necessary to
upgrade nursing education to broaden its scope, and provide more
exceptional patient care and job satisfaction. The relevant literature
for the article was gathered from the Cumulative Index of Nursing and
Allied Health Literature (CINAHL), PubMed and Google Scholar. The
search was restricted to the English language and 2020 as the year
of publication. Health professionals in the field were also interviewed
for their opinion on improving the Sri Lankan nursing curriculum.
Enhancing nursing education is one of the best investments a country
can make towards a quality healthcare system. Training is crucial.
The implementation of new approaches to nursing education will
standardize and develop the quality of nursing professionalism in
Sri Lanka.

\section{KEY WORDS:}

Nursing education, evidence-based nursing practice, holistic nursing, emotional intelligence, psychological empowerment, language proficiency, information technology.

\footnotetext{
Suggested Citation: Kumara, W. G. C., \& Sudusinghe, W. S. (2021). Improving nursing education in Sri Lanka to take on new challenges faced by global healthcare systems. University of Colombo Review (New Series III), 2(1), $119-137$.

(C) 2021 The Authors. This work is licenced under a Creative Commons Attribution 4.0 International Licence which permits unrestricted use, distribution, and reproduction in any medium, provided the original work is properly cited.
} 


\section{Introduction}

Education serves as a means of providing students access to knowledge and aims to empower them through social transformation (Noro et al., 2015). It is subjected to frequent changes due to the influence of economic and socio-political factors which occur throughout the world (Li, 2016; Rodrigues et al., 2016). A workforce of trained and efficient professionals flexible enough to work in diverse working environments has become a requirement (Marran et al., 2015; Noro et al., 2015; Wang \& Torrisi-Steele, 2015). Health care education is no exception and is, in fact, a critical area of higher education that requires adjustment to meet current global trends. Enhancing nursing education plays a significant role in this regard. In a world where there is a deficit of nurses to meet these global trends, novel mechanisms are necessary to tackle the multi-dimensional health risks that have arisen in the world today (Jamshidi et al., 2012).

Today, the world has moved away from the traditional role expected of a nurse and instead, requires nurses who can function in a multidisciplinary environment (Atwal $\&$ Caldwell, 2006). In addition to their conventional role of care, nurses are expected to perform well in leadership, advocacy, research, management and illness prevention (Fukada, 2018). Therefore, it has become a global necessity to upgrade nursing education to meet these expanded needs of the healthcare system. Accordingly, Sri Lanka also needs to implement various mechanisms to enhance the quality of its nursing education in parallel with global trends.

The tradition of British nursing heavily influenced nursing services in Sri Lanka during the early stages. It paved the way for adapting the apprenticeship model into Sri Lankan hospital-based nursing education. Nevertheless, this model was also the main reason for transferring nursing education into separate Nursing Schools. In 1939, nursing education in Sri-Lanka reached a milestone with the establishment of the School of Nursing in Colombo. Several decades later, in 2014, sixteen nursing schools were established in Sri Lanka to facilitate a three-year diploma in nursing at pre-registration level. Following extensive reviews on the proposals made by pioneering nursing leaders and authorities, the University Grants Commission of Sri Lanka established a four-year, pre-registration degree program leading to a BSc. in nursing at five state universities. (Jayasekara \& Amarasekara, 2015). The Open University of Sri Lanka began a BSc. nursing degree for nurses already registered with the Ministry of Health. Therefore, as proposed in the National Health Policy of 1992, nursing education in Sri Lanka was upgraded to degree level. This recommendation had also been reiterated in the National Strategic Plan for Nursing and Midwifery Development 2001-2010 (Jayasekara \& Amarasekara, 2015).

Recently, a few private universities in Sri Lanka commenced awarding a Master's degree in Nursing for candidates who have completed the BSc. degree. Currently, nursing education in Sri Lanka reached a milestone with $\mathrm{PhD}$ holders in nursing providing their expertise to the enrichment of nursing education in both local and international contexts. However, the existing nursing curriculum in Sri Lanka has less emphasis on research, evidence-based practice, therapeutic communication skills, exposure to advanced technology and computer literacy. 
In many developed countries, there is a favorable ratio between the number of patients and the nurses. However, in Sri Lanka, there is a deficiency in the number of nurses in relation to the number of patients. Hence it has become imperative to increase the number of students entering the nursing profession. If nursing education in Sri Lanka is modified and upgraded, these changes themselves will become motivating factors for those who want to enter the nursing profession. Further, if Sri Lankan nurses are provided exposure to internationally recognized nursing education and training, they can extend their services both within Sri Lanka and internationally.

This article analyzes some new approaches and suggests novel mechanisms that can be implemented in Sri Lanka towards upgrading nursing education to meet global demands. Improving English proficiency, enhancing therapeutic communication skills, implementing a holistic approach in nursing education and patient care, and improving psychological empowerment and assertiveness skills are some of these. In addition, novel approaches on multiple intelligences, learning styles, emotional intelligence, and improving counselling skills are critical interventions. Such topics have become even more necessary given the COVID-19 global pandemic.

\section{Methodology}

The relevant literature for this article was drawn from the Cumulative Index of Nursing and Allied Health Literature (CINAHL), PubMed and Google Scholar. The search was restricted to English language articles published until 2020, as there were practical difficulties in finding Sinhala and Tamil language articles related to the topic. Experienced chief nursing officers, special grade nursing officers, consultant psychiatrists, clinical psychologists, nurse educators and nurses were also interviewed, in a semistructured interview process, to gather information about areas that required improvement in the nursing curriculum. Keywords used to identify the relevant sources were: "nursing education", "nursing students", "evidence-based practice", "integral nursing", "emotional intelligence", "psychological empowerment", "language proficiency" and "information technology". Boolean operators (AND, OR and NOT) were used to combine the search on the above key terms.

\section{A Holistic Approach to Nursing Education}

According to the World Health Organization (WHO), being healthy does not merely mean leading a life free of diseases. Rather, it is to be gained through physical, mental and social wellbeing (WHO, n. d.). The role a nurse plays in achieving this goal is noteworthy. The nursing profession is meant to provide quality, self-regulating health care for all individuals regardless of their age, class, caste or gender. Further, a nurse is supposed to focus on the quality of life of every individual through comprehensive nursing care (Nursing and Midwifery, n. d.). Therefore, nursing education should aim to create such nurses capable of providing holistic care to patients.

Integral nursing is the core of successful nursing, and being an integral nurse means he/she is capable of providing extensive and highly professional care to people 
throughout the world (Dossey, 2008). According to Dossey, the integral process is a comprehensive way to organize multiple phenomena of human experience and reality from four perspectives - individual interior, individual exterior, collective interior and collective exterior. The individual interior is the "I" of nursing, the individual exterior is the "it" of nursing, the collective interior is the "we" of nursing, and the collective exterior is the "its" of nursing (Dossey, 2008). The "I" includes the world of the individual's subjective interior experiences. These are thoughts, emotions, memories, perceptions, immediate sensations and states of mind. "It" is the objective outer reality of the individual. It includes the material body, integral patient care plans, skills development, behaviors, leadership skills and integral life practices, and anything that we can touch or observe scientifically in time and space. Marking an extraordinary movement in health care history, the theory of critical nursing also revolutionized the profession by making it more systematic through educational enhancement, encouraging research, and policymaking to obtain widespread success (Dossey, 2008). Integral nursing includes the "it" of new behaviors, integral assessment and care plans, leadership, and skills development (Dossey, 2008).

The "we" that Dossey (2008) writes of, denotes an interior collective and how we share our cultural background, stories, values, meanings, visions, languages, and relationships, and how we can form partnerships to achieve a healing mission. It can lessen our fragmentation and enhance collaborative practice and in-depth dialogue around things that matter (Dossey, 2008). The "its" indicates the world of collective, exterior things, including social systems/structures, networks, organizational structures, information technology, regulatory structures and any aspect of the technological environment or the natural world. Integral nursing identifies the "its" as the structure that can be enhanced to create more integral awareness and integral partnerships to achieve health and healing both locally and globally (Dossey, 2008).

Integral nursing paves the way to a wholesome awareness of healing and the nature of humans. It becomes one of the greatest strengths for nurses to provide substantial care for patients with empathy. Integral nursing provides a sound framework within which nurses offer the best healthcare service, thereby enhancing their own satisfaction as well as that of the patients and their families. It has a direct impact on the functioning of the entire healthcare system (Fiandt et al., 2003). Integral nursing improves a nurse's personality and professionalism. It produces nurses with high self-realization who will, thereafter, generate a more comprehensive and quality relationship with patients (Rasheed et al., 2019). However, this theory of integral nursing has not been sufficiently included, as yet, in the current nursing curriculum in Sri Lanka. Since the theory of integral nursing is an in-depth process that extends our holistic understanding and connections, there should be more prominence given to integrating this theory into the nursing curriculum.

As noted by the health care professionals interviewed for this study, it became clear that some nurses and nursing students today, lack the core skills required for holistic nursing care. For instance, one of the Chief Nursing Officers stated, "[t]he modern generation of nurses seems to lack iconic nursing qualities like empathy, mutual understanding, and respect towards the patients" and suggested that "nursing curricula should be enriched 
with more practical approaches in inculcating these qualities within all the modules in all academic years". Moreover, one of the consultants suggested that new methods of teaching like problem-based learning (PBL) should be introduced to existing curricula and practical examinations held to assess these qualities. Even though topics such as empathy, mutual understanding and respect are discussed in first year modules, they receive less prominence in subsequent modules. Integrating a culturally appropriate nursing care model throughout each academic year towards facilitating holistic nursing care (Jayasekara \& Amarasekara, 2015) becomes, therefore, all the more important. It is essential, moreover, to increase the significance of subjects like psychology and sociology in the nursing curriculum which will strengthen students' awareness of patients' needs and social issues.

\section{Evidence-Based Practice in Nursing Education}

Evidence-based practice is defined as an approach to medicine, education and other disciplines that emphasizes the practical application of findings from the best available current research (Autores, 2010). Evidence-based nursing practices and policies play a crucial role in enhancing the quality of healthcare systems, individuals and group care providers (Correa-de-Araujo, 2016). Nurses have a significant and highly influential role to play in the public health encounters of current healthcare systems. They form the principal constituency of the health workforce (European Strategic Directions, 2015). Strategic performers provide operative, resourceful, reachable, satisfactory, patient-based, justifiable and innocuous healthcare services (WHO, 2018). It is widely recognized that quality healthcare services necessitate clinical decision-making in nursing, midwifery, and care coordination grounded on evidence (European Strategic Directions, 2015). Accessible evidence should be applied when enhancing features of excellence in health care and augmenting evidence-based practice (European Strategic Directions, 2015). The nursing and midwifery professions are key to accomplishing such evidence-based practice (Jun et al., 2016; Pearson et al., 2012; Stevens, 2013).

Further, with the development of modern technology, healthcare has also undergone tremendous changes, widening horizons for new explorations, research and innovation (Thimbleby, 2013). With the COVID-19 pandemic, it has become essential to upgrade nursing education to meet international standards (Morin, 2012). Despite some favorable improvements in nursing education in Sri Lanka (i.e., commencement of bachelor's and master's nursing degree programs, annual nursing research symposiums, increased $\mathrm{PhD}$ scholarships for nursing graduates) significant barriers still exist in evidence-based practice and education. Three immediate and internationally acknowledged challenges, which also apply in the Sri Lankan case, are, 1) restrictions within health care systems leading to less support for nursing education including the improvement of relevant research, 2) prejudice against nurses' advancement in their practice, and 3) workforce decline (Correa-deAraujo, 2016). Other influences explicitly motivating or limiting evidence-based nursing include nurses' basic research training, beliefs, and complications faced with eliciting and integrating patient preferences (Correa-de-Araujo, 2016). 
There are a few accomplishments worth noting about Sri Lanka's progress on evidence-based nursing practice. Firstly, the pre-registration of nurses in Sri-Lanka is shifting from diploma level to a university bachelor's degree on par with many countries worldwide (Jayasekara \& Amarasekara, 2015). However, gaps remain. Currently, nursing students are exposed to a system of teaching that is heavily dependent on theory. Greater emphasis is required, therefore, on student involvement in evidence-based practice from the first academic year onwards. The nursing curricula should also be updated to cater to the current requirements of healthcare. This can be attained by integrating the concept of comprehensive training and including more research into nursing syllabuses so that nursing students utilize evidence-based practice for patient care (Jayasekara \& Amarasekara, 2015).

Secondly, it is mandatory to improve skills required for the 21 st Century among nursing students. These skills can be categorized into three groups: learning skills, literacy skills and life skills. Learning skills include creativity, critical thinking, collaboration, and communication (Lamb et al., 2017) and help nurses to adapt to any situation and to improve in the workplace. Literacy skills include information literacy, media literacy and technology literacy (Lamb et al., 2017) and help individuals to be challenging and independent thinkers in evidence-based practice. The third category is life skills which includes flexibility, leadership, imitation, productivity and social skills which can be applied in both their personal and professional lives (Lamb et al., 2017). If nurses can be equipped with these three categories of skills, evidence-based practice will ensue. Therefore, integrating these skills into existing nursing curricula from the beginning of the academic program is essential.

\section{Therapeutic Communication and Counselling skills}

In general, all professions related to healthcare are classified as highly stressful, and among them, nursing is considered one of the most stressful (Cottrell, 2001; FirthCozens, 1999). Therefore, it is of great importance that nurses develop their therapeutic communication skills and counselling skills in the best interest of their patients and themselves. Eventually, this will lead to a high level of satisfaction for both the patient and the nurse (Kettunen et al., 2000; Marita et al., 1999). To patients, nurses are the closest healthcare providers. Hence, they can heavily influence the psychology of patients. The way they treat patients play a dominant role in patient satisfaction. Therefore, nurses must provide medical support as well as create a solid therapeutic relationship with patients. This can be achieved by paying attention to the patients' concerns, showing empathy, and providing comfort by understanding their grievances (Kruijver et al., 2000). Additionally, nurses have to respond to crises involving critically ill patients and their family members. In this situation nurses need to master counselling skills that will assist in breaking bad news and providing comfort to family members. All these need to be done in such a way that the self-determination and autonomy of the patient remain unharmed (Abbaszadeh et al., 2014).

The current nursing curriculum includes modules such as communication skills and mental health nursing with the objective of improving therapeutic communication and 
counselling skills among nursing students. However, these skills are inadequately taught throughout the academic program. The application of communication and counselling skills are key practices in the management of many medical, surgical, pediatric, obstetric and gynecological conditions. Yet, as one of the chief nursing officers interviewed stated, "nursing students of the modern generation lack application of therapeutic communication skills and counselling skills when they face patients with medical, surgical, pediatric, obstetric and gynecological conditions". It is evident from this view that therapeutic and counselling skills should also be incorporated extensively into modules like medical and surgical nursing, pediatric nursing, and gynecology and obstetrics nursing through problembased learning. This will promote critical thinking, communication, and problem-solving skills among nursing students in a vast array of situations.

Nurses play a significant role in providing the necessary emotional support to both patients and their family members. Therefore, it is essential to modify the nursing education curriculum to integrate topics such as empathy and mutual respect which will enable nurses to counsel patients and their families in overcoming chronic illness, disability and bereavement. This constitutes a critical element in providing holistic care to patients.

\section{Assertiveness and Psychological Empowerment}

Every person has a unique communication style, a way in which they interact and exchange information with others. These communication styles, however, can be broadly placed into four categories - passive, assertive, aggressive and passive-aggressive (Alvernia University, 2018). The passive style marks that the events or actions of others are met without resistance. People consider the passive style to be weak, and if it is someone's main communication style, that individual is seen as shy and ineffective (Maloney \& Moore, 2019). The aggressive style has two definitions. The first - "ready or likely to attack or confront" - indicates synonyms such as "hostile", "antagonistic", or "belligerent". The second stands for "pursuing one's aims and interests forcefully, sometimes unduly", synonymous with "forceful", "vigorous", "energetic", "bold", or "enterprising". The first definition is negative, while the second is more active than threatening (Maloney \& Moore, 2019). Passive-aggressive communication is a style in which individuals appear passive on the surface but really act out anger in a subtle and indirect way. The assertive style is considered the most effective (Taghavi Larijani et al., 2014). Assertiveness is defined as an adaptive style of exchanging information where people show their feelings and requirements directly while maintaining respect for others. Inability to be assertive in certain situations can lead to depression and anxiety (APA Dictionary of Psychology, 2018).

Health professionals require well developed communication skills to promote and maintain good patient interaction and safety (Omura et al., 2016). Assertiveness among nurses is a valuable component for successful professional practice (Kilkus, 1993; McCabe \& Timmins, 2003). However, aggression or violence in the workplace leads to serious consequences for nurses, their patients, patient care, and the organization as a whole (Edward et al., 2014). It is reported that nurses experience sadness, shock, confusion, anger and embarrassment following such aggressive incidents (Edward et al., 2014). Therefore, 
assertiveness is necessary for effective communication between nurse and patient, and helps build the nurses' confidence (McCabe \& Timmins, 2003). It should not, however, lead to aggression. The absence of assertiveness, on the other hand, affects patient communication and care (Poroch \& McIntosh, 1995). Patients tend to notice a lack of confidence in the nurse which weakens trust (Timmins \& McCabe, 2004). It has been noted that Sri Lankan nurses are submissive when it comes to health care managers even though they play various roles in the hospital setting as team builders, advocates, decision-makers and managers (De Silva, 2010). This is, perhaps, due to the hierarchical structure of the health management system in Sri Lanka. It is paramount, therefore, to improve the assertive communication skills of nursing students so that they will be confident in the future and this should be part of the nursing curriculum. The current nursing curriculum pays less attention to developing assertiveness, and nurses are inadequately trained to communicate with confidence in practical situations.

Psychological empowerment, defined as "intrinsic task motivation reflecting a sense of self-control in relation to one's work and an active involvement with one's work role" (Spreitzer, 1995), plays an equally important role in improving assertiveness. It is generally identified as the primary standpoint of a person to his/her work environment and role of the specific organization, and comprises four cognitive understandings: meaning, competence, self-determination and impact (Spreitzer, 1995). Psychological empowerment is associated with low stress, burnout and turnover intention, high organizational commitment and job satisfaction (Ibrahem et al., 2013; Ouyang et al., 2015; Oyeleye et al., 2013).

Psychological empowerment becomes a potent force when mediating nursing outcomes and structural empowerment leading to higher job satisfaction. Further, psychological empowerment is integral to motivation. It enhances self-confidence (Conger \& Kanungo, 1988). Nurses who possess access to structural empowerment tend to have more faith in their capacity to contribute meaningfully to their workplace than those without. These positive beliefs subsequently intensify job satisfaction (Laschinger et al., 2004).

Psychological empowerment also facilitates autonomous decision-making amongst nursing students and goes hand in hand with encouraging innovative thinking and personalized learning instead of standardized rote learning. As suggested by the Joint Commission on Accreditation of Health Organizations, nursing education should offer programs that empower individuals. In today's complex health care system, it is time to assess whether nursing education creates student nurses who work autonomously and can meet the challenging roles the nursing profession currently requires (Ibrahim, 2011).

The current nursing curriculum in Sri Lanka lacks modules on the psychological empowerment of nurses. Even though it includes theoretical teaching on areas like leadership and management, the connectivity of these to clinical and practical settings is not adequately taught and learnt. As a result, graduate nurses end up with low job satisfaction and high stress once they become professional nurses. Therefore, it is recommended that a well-organized leadership and management internship program before graduation which would enhance the psychological empowerment of nursing students be mainstreamed into nursing education. 


\section{Improving English Language Proficiency}

As society moves ahead in an era where every aspect of society is governed by technology, English language proficiency has become the dominant agent that mediates globalization and modernization (Fischer et al., 2019). With increasing diversification and the frequent encounters of people who belong to different cultures, there is an evergrowing demand for second language acquisition. This has led to a demand for improved second language proficiency for both receiving and delivering efficient healthcare services (Meuter et al., 2015) and successful professionalism (Sumskas et al., 2010). Given the role of English in empowering individuals on a large scale, there is an ever-growing demand for improving English language proficiency, especially among non-native speakers of English (Rameez, 2019). Lack of English language skills provokes anxiety, fear and stress and hinders the growth and improvement of many non-native speakers of English, including nursing professionals (Khawaja et al., 2017). English language proficiency is also a critical tool for exploring new knowledge and internationally standardized healthcare (Squires \& Jacobs, 2016). In Sri Lankan nursing education, however, interventions to improve the level of language competency among nursing students are deficient. Therefore, their anxiety in relation to English language skills remains unaddressed.

The current nursing curricula on English teaching is primarily aimed at standard English rather than English for specific purposes (ESP). English language teaching should be focused mainly on nursing terminology and the use of English in nursing-related scenarios. Furthermore, in many Sri Lankan universities, nursing students are provided only a few weeks of English teaching during their orientation program whereas English should be taught in all academic years. Nurses with better English language competency will receive priority in the international context. A research study (Ryan et al., 1998) conducted in Taiwan on nursing education found that a lack of English language proficiency negatively impacted their presentation skills, research and assignment writing, communication skills, and level of confidence. They had referencing and plagiarism problems. The study also found that these students had a low level of active participation at seminar discussions due to their lack of communication skills in English. Above all, they were reluctant to speak in English in front of native speakers. This inability to express their thoughts in English became a painful experience for many nursing students (Ryan et al., 1998).

As most nursing students in Sri Lanka are not native English language speakers, similar problems are present. Improving the English language competency of nursing students would, therefore, enhance the nursing profession and healthcare in general. It will strengthen the self-esteem and psychological empowerment of nursing students and open up opportunities for pursuing further studies at an international level.

\section{Addressing Multiple Intelligences and Learning Styles}

In the 20th Century, traditional education systems were revolutionized when increased significance was given to learner-centered education (Bakić-Mirić, 2010). In line with this, nurse educators also try their best to create learning opportunities that are interactive and applicable to the requirements of their students (Amerson, 2006). However, 
students' academic performance depends on multiple intelligence and learning styles (Hernandez Suarez et al., 2019).

According to Gardner (1983), intelligence cannot be termed as general intelligence but is multifactorial. According to theory on multiple intelligence, every person possesses all nine dimensions of intelligence: linguistic, mathematical, spatial, bodily-kinesthetic intelligence, naturalist intelligence, interpersonal intelligence, musical intelligence, and intrapersonal intelligence (Sternberg, 2012). Logical-mathematical intelligence is identified as the competence to identify designs, reason deductively and reflect rationally. This intelligence is common in scientific and mathematical thinking (Sternberg, 2012). In the field of nursing, complex problems are solved with the aid of logical-mathematical intelligence. It is used to develop care plans, assess the quality of care, create different schedules, obtain pharmacological measurements, and understand the science behind contributing disciplines such as biology, physics and chemistry (Phaneuf, 2006).

Linguistic intelligence comprises fluency in language. It comprises the capacity to work out language efficiently to express oneself effectively. Further, it allows one to use language as a way to recall information. Traditionally, this type of intelligence was cultivated by motivating students to write. Verbal communication, which is of greater significance to nursing, was less emphasized. Warm and functional communication are classified as critical in nursing and an indispensable part of the therapeutic relationship (Phaneuf, 2006). This is yet another reason why language and communication must be emphasized in nursing education.

Spatial intelligence facilitates the ability to generate, retain, retrieve, and transform well-structured visual images (Lohman, 1996). In nursing, this type of intelligence plays a significant role in providing a soothing environment for the patient (Phaneuf, 2006) and "mental mapping" for nursing care plans (Parvari et al., 2017). Musical intelligence which enables one to identify and create musical pitches, tones, and rhythms has the potential to provide psychological relief to the patient. When the nurse uses a soft and soothing voice, patient care flourishes and there is psychological healing (Phaneuf, 2006). Bodilykinesthetic intelligence permits one to manage one's own bodily actions using one's psychological capabilities. Kinesthetic intelligence contests the claim that psychological and physical activities are unconnected (Sternberg, 2012). In nursing, kinesthetic intelligence is necessary for nursing care procedures such as providing hygiene, and lifting and moving patients (Phaneuf, 2006).

Interpersonal intelligence provides the capacity to realize and distinguish the emotions and purposes of others (Sternberg, 2012). It is of greater significance in nursing care as it facilitates the nurse to listen to the patient, helps in maintaining the team spirit, assists in the process of conflict resolution and improves organizing and leadership skills at different levels (Phaneuf, 2006). Intrapersonal intelligence, on the other hand, leads to the realization of one's own emotions and inspirations (Sternberg, 2012), and provides nurses with the ability to improve metacognition, reevaluate their own actions, estimate their own significance and make any desirable corrections (Phaneuf, 2006).

Learning styles has been discussed broadly in experimental studies on the continually changing processes of learning (Samarakoon et al., 2013). Honey and Mumford (1992) 
produced a learning styles questionnaire (LSQ) based on the idea that the best way to determine learning styles is to query students on how they learn and identified four main learning styles - activist, reflector, theorist, and pragmatist. According to their study, people with an activist style have updated knowledge and understanding, are keen for up-to-date information, make good speeches, and do not tolerate monotonous, non-interactive pursuits such as sitting still for an extended period or listening to explanations without interactions. They prefer group discussions and innovative activities. They are good at problem-solving, maintaining good interpersonal relationships, and have excellent communication skills.

The reflective learner prefers to gather comprehensive data and information. S/he is cautious, and because of that, often tends to reflect upon findings before taking action. Those who fall into the category of the theorist style of learning are inquisitive and curious for clarifications. Theorists prefer complexity and to prove things methodically. They prefer to have clearly defined goals. Learners who adopt a pragmatic style are curious to explore and discover new strategies and find out whether these strategies are effective and valid. They prefer to focus on validated practical problems and problem-solving situations (Czepula et al., 2016).

Addressing multiple intelligence and learning styles of nursing students would play a significant role in developing the nursing profession since nurses have to adapt to dynamic situations in the clinical setup. However, the current nursing curriculum has limited measurements to assess learning styles and multiple intelligences and therefore, does not have a proper mechanism to address them. This is a barrier to understanding students with different potentialities.

Nursing students are the future generation of the nursing profession. Therefore, it is essential that they be self-aware, and alert to their multiple intelligences and learning styles so that they reach their maximum potential. Continuous assessment of these intelligences and learning styles should be planned, and relevant changes in teaching-learning activities made throughout all academic years. Pilot studies on how to teach and assess such modules can be conducted before making the necessary changes to the existing nursing curriculum.

\section{Emotional Intelligence in Nursing}

Emotional intelligence is a critical skill. Five main attributes govern emotional intelligence: self-awareness, self-regulation, motivation, social skills, and empathy. Many research studies have proved that emotional intelligence has a significant influence on the nurse-patient relationship. It is relevant to everyone in the nursing profession, beginning with nursing students. Patient satisfaction and outcomes can be enhanced when healthcare professionals start to express compassion (Nightingale et al., 2018). Hence improving the emotional intelligence of nurses is key to their success. (Petrides \& Furnham, 2000). Most of the available literature on this topic focuses, however, on the emotional intelligence of nursing leaders and executives (Bulmer Smith et al., 2009), while only a limited number explore the emotional intelligence of nursing students (Benson et al., 2010; Li et al., 2015; Montes-Berges \& Augusto, 2007; Rochester et al., 2005). The latter calls, therefore, for further research. 
When nurses master emotional intelligence skills, they will maintain healthy and productive relationships with patients, their families, and other colleagues. Therefore, nursing education should provide them with opportunities to enhance their competencies in self-awareness, emotional awareness, accurate self-assessment and self-confidence. Each of these skills is critical to effective healthcare interventions. With these skills, the nursing students will have better self-control, trustworthiness, adaptability and innovativeness (Fitzpatrick, 2016). These skills can be acquired by introducing leadership training programs and events of self-discovery into the nursing curricula. Frequent summative assessments of emotional intelligence can be conducted by asking students to submit a reflective portfolio and logbook for every clinical placement. Integrating emotional intelligence into the curriculum in this way would enrich students' affective domain, and create future nurses with sound values.

\section{Information Technology (IT) in Nursing Education}

In the modern world, technology has come to dominate every aspect of human life including healthcare (Thimbleby, 2013). Currently, web-based education has begun to play an essential role because of the outbreak of the COVID-19 pandemic (Mukhtar et al., 2020). Distance learning and web-based teaching have become massively helpful; therefore, the Sri Lankan nursing curriculum should also be upgraded to target improvement of IT knowledge and skills among nursing students. This can be achieved by making IT one of the core subjects of the nursing students' curriculum (Huston, 2013). IT knowledge and skills will enable students to access global knowledge, improve evidence-based practice, and enhance their research skills. It will give them access to e-libraries, IT classrooms, video conferencing, and IT training. Nursing students will thereby become competent in catering to the needs of global healthcare. Towards this, loan schemes at a low interest rate for the purchase of laptops and data plans should be offered to those students with financial difficulties.

\section{Conclusion}

Nursing education plays a crucial role in the provision of holistic nursing care, and this education depends on the content of the educational programs, the teaching methods, and the educators' competence (Zamanzadeh et al., 2015). The theory of integral nursing addresses how nurses can enhance their self-awareness, wholeness, and nourish their personal and professional goals (Dossey, 2008). It was noted, however, that the significance given to integral nursing is low in the current nursing curriculum in Sri Lanka.

Therapeutic communication is a fundamental component of nursing, and a nurse with excellent communication and counselling skills will match the patient's therapeutic goals well. Therefore, developing communication and counselling skills among nursing students is essential (Abdolrahimi et al., 2017; Gutiérrez-Puertas et al., 2020). A competency-based practice in counselling is achieved through self-exploration, supervised work, acquired skills and the study of theory (Jones, 1995). The current nursing curriculum in Sri Lanka requires more practical hours of training in this regard. 
Evidence-based nursing practices and policies also play an important role in enhancing the quality of healthcare systems and providers. More research and researchbased activities are necessary to procure findings on evidence-based nursing care in the Sri Lankan context. Promoting nursing research forums in hospitals and reinforcing the nurses who contribute to local and international research would also be important steps in this direction.

Today's nurses are required to be more assertive, emotionally intelligent, and psychologically empowered. In this regard, there are multiple advantages to strengthening communication skills through assertiveness training programs (Nakamura et al., 2017). As nurses with high emotional intelligence have been shown to enjoy high levels of job satisfaction (Thiruchelvi \& Supriya, 2009), education, training, and assessment of emotional intelligence must be considered priorities.

The clinical competency of pre-registration nursing students has raised questions about clinical skills acquisition within nursing education (Sheahan et al., 2015). A teaching environment that accounts for multiple intelligences and learning styles is crucial for producing theoretically and clinically competent nurses. Similarly, literacy in IT and English language fluency are growing needs of the health industry. However, there are gaps in current Sri Lankan nursing curricula in this regard. Therefore, it is the responsibility of nursing educators and administrators to develop a conducive teaching and learning environment for nursing students to develop each of these skills.

Nurses are one of the greatest assets in any healthcare system. Thus, enhancing nursing education in a country is one of the best investments it can make. When nursing students are exposed to various professional training environments, they become highly competent and flexible, with the ability to meet any challenge in their careers. Professionalism and a holistic approach in treating patients must be mastered from the beginning. Towards this, counselling skills, therapeutic communication skills, assertiveness and psychological empowerment are important. The integration of evidence-based practice into nursing education will also introduce new horizons for research and innovative thinking. While Sri-Lankan nursing education has reached various milestones, the implementation of the above will both standardize and upgrade nursing education leading to highly qualified and professional nurses who will be a blessing to the entire country.

\section{References}

Abbaszadeh, A., Ehsani, S. R., Begjani, J., Kaji, M. A., Dopolani, F. N., Nejati, A., \& Mohammadnejad, E. (2014). Nurses' perspectives on breaking bad news to patients and their families: A qualitative content analysis. Journal of Medical Ethics and History of Medicine, 7. https://www.ncbi.nlm.nih.gov/pmc/articles/PMC4263382/

Abdolrahimi, M., Ghiyasvandian, S., Zakerimoghadam, M., \& Ebadi, A. (2017). Therapeutic communication in nursing students: A Walker \& Avant concept analysis. Electronic Physician, 9(8), 4968-4977. https://doi.org/10.19082/4968 
Alvernia University. (2018, March 27). 4 Types of Communication Styles. Alvernia Online. https://online.alvernia.edu/articles/4-types-communication-styles/

Amerson, R. (2006). Energizing the nursing lecture: Application of the theory of multiple intelligence learning. Nursing Education Perspectives, 27(4), 194-196.

Assertiveness - APA Dictionary of Psychology. (n.d.). Retrieved July 16, 2018, from https://dictionary.apa.org/assertiveness

Atwal, A., \& Caldwell, K. (2006). Nurses' perceptions of multidisciplinary team work in acute health-care. International Journal of Nursing Practice, 12(6), 359-365. https://doi.org/10.1111/j.1440-172X.2006.00595.x

Autores, V. (2010). Oxford Dictionary of English (3rd revised ed.). Oxford University Press España, S.A.

Bakić-Mirić, N. (2010). Implementation of multiple intelligences theory in the English language course syllabus at the University of Niš Medical School. Srp Arh Celok Lek., 6.

Benson, G., Ploeg, J., \& Brown, B. (2010). A cross-sectional study of emotional intelligence in baccalaureate nursing students. Nurse Education Today, 30(1), 49-53.

https://doi.org/10.1016/j.nedt.2009.06.006

Bulmer Smith, K., Profetto-McGrath, J., \& Cummings, G. G. (2009). Emotional intelligence and nursing: An integrative literature review. International Journal of Nursing Studies, 46(12), 1624-1636. https://doi.org/10.1016/j.ijnurstu.2009.05.024

Conger, J. A., \& Kanungo, R. N. (1988). The empowerment process: Integrating theory and practice. The Academy of Management Review, 13(3), 471-482. https://doi.org/10.2307/258093

Correa-de-Araujo, R. (2016). Evidence-based practice in the United States: Challenges, progress, and future directions. Health Care for Women International, 37(1), 2-22. https://doi.org/10.1080/07399332.2015.1102269

Cottrell, S. (2001). Occupational stress and job satisfaction in mental health nursing: Focused interventions through evidence-based assessment. Journal of Psychiatric and Mental Health Nursing, 8(2), 157-164. https://doi.org/10.1046/j.1365-2850.2001.00373.x

Czepula, A. I., Bottacin, W. E., Hipólito, E., Baptista, D. R., Pontarolo, R., \& Correr, C. J. (2016). Predominant learning styles among pharmacy students at the Federal University of Paraná, Brazil. Pharmacy Practice, 14(1), 650. https://doi.org/10.18549/PharmPract.2016.01.650

De Silva, B. S. (2010). Health-care system and nursing in Sri Lanka: An ethnography study. Nursing \& Health Sciences, 12, 33-38. https://doi.org/10.1111/j.1442-2018.2009.00482.x

Dossey, B. M. (2008). Theory of integral nursing. Advances in Nursing Science, 31(1), E52-E73. https://doi.org/10.1097/01.ANS.0000311536.11683.0a

Edward, K., Ousey, K., Warelow, P., \& Lui, S. (2014). Nursing and aggression in the workplace: A systematic review. British Journal of Nursing (Mark Allen Publishing), 23(12), 653-654, 656-659. https://doi.org/10.12968/bjon.2014.23.12.653 
European strategic directions for strengthening nursing and midwifery towards Health 2020 goals. (2015). World Health Organization, Europe. Retrieved August 17, 2019, from http://www.euro.who.int/en/health-topics/Health-systems/nursing-and-midwifery/ publications/2015/european-strategic-directions-for-strengthening-nursing-and-midwiferytowards-health-2020-goals

Fiandt, K., Forman, J., Megel, M. E., Pakieser, R. A., \& Burge, S. (2003). Integral nursing: An emerging framework for engaging the evolution of the profession. Nursing Outlook, 51(3), 130137. https://doi.org/10.1016/S0029-6554(03)00080-0

Firth-Cozens, J. (1999). Stress in health professionals: Psychological and organisational causes and interventions. Wiley.

Fischer, S., Spoerri, C. M., Gmuer, A., Wingeier, M., Nater, U. M., Gaab, J., Ehlert, U., \& Ditzen, B. (2019). Psychobiological impact of speaking a second language in healthy young men. Stress (Amsterdam, Netherlands), 22(3), 403-407. https://doi.org/10.1080/10253890.2019.1575805

Fitzpatrick, J. J. (2016). Helping nursing students develop and expand their emotional intelligence: Nursing Education Perspectives, 37(3), 124. https://doi.org/10.1097/01.NEP.0000000000000020

Fukada, M. (2018). Nursing competency: Definition, structure and development. Yonago Acta Medica, 61(1), 001-007. https://doi.org/10.33160/yam.2018.03.001

Gardner, H. (1983). Frames of mind: The theory of multiple intelligences. Basic Books.

Gutiérrez-Puertas, L., Márquez-Hernández, V. V., Gutiérrez-Puertas, V., Granados-Gámez, G., \& Aguilera-Manrique, G. (2020). Educational interventions for nursing students to develop communication skills with patients: A systematic review. International Journal of Environmental Research and Public Health, 17(7), 2241. https://doi.org/10.3390/ijerph17072241

Hernandez Suarez, C. A., Núñez, R., \& Rincón, G. (2019). Multiple intelligences and academic performance in basic education students: An analysis of main components. Journal of Physics: Conference Series, 1388, 012047. https://doi.org/10.1088/1742-6596/1388/1/012047

Honey, P., \& Mumford, A. (1992). The manual of learning styles (3rd ed.). Peter Honey Publications.

Huston, C. (2013). The impact of emerging technology on nursing care: Warp speed ahead. Online Journal of Issues in Nursing, 18(2), 1.

Ibrahem, S. Z., Elhoseeny, T., \& Mahmoud, R. A. (2013). Workplace empowerment and organizational commitment among nurses working at the Main University Hospital, Alexandria, Egypt: Journal of the Egyptian Public Health Association, 88(2), 90-96.

https://doi.org/10.1097/01.EPX.0000430957.52814.8a

Ibrahim, S. A. E. A. (2011). Factors affecting assertiveness among student nurses. Nurse Education Today, 31(4), 356-360. https://doi.org/10.1016/j.nedt.2010.07.006

Jamshidi, L., Mehrdad, A. G., \& Jamshidi, S. (2012). Assessing nursing students' knowledge and attitudes about computers and the internet. Procedia - Social and Behavioral Sciences, 46, 1371-1374. https://doi.org/10.1016/j.sbspro.2012.05.304 
Jayasekara, \& Amarasekara. (2015, June 29). Nursing education in Sri Lanka: Challenges and vision for the future. 3rd Annual Worldwide Nursing Conference (WNC 2015). Annual Worldwide Nursing Conference. https://doi.org/10.5176/2315-4330_WNC15.47

Jones, A. (1995). Assessing counselling skills in nurse education. Professional Nurse (London, England), 10(7), 418-420.

Jun, J., Kovner, C. T., \& Stimpfel, A. W. (2016). Barriers and facilitators of nurses' use of clinical practice guidelines: An integrative review. International Journal of Nursing Studies, 60, 54-68. https://doi.org/10.1016/j.ijnurstu.2016.03.006

Kettunen, T., Poskiparta, M., \& Liimatainen, L. (2000). Communicator styles of hospital patients during nurse-patient counseling. Patient Education and Counseling, 41(2), 161-180. https://doi.org/10.1016/s0738-3991(99)00076-2

Khawaja, N. G., Chan, S., \& Stein, G. (2017). The relationship between second language anxiety and international nursing students stress. https://doi.org/10.5281/ZENODO.570021

Kilkus, S. P. (1993). Assertiveness among professional nurses. Journal of Advanced Nursing, 18(8), $1324-1330$.

Kruijver, I. P., Kerkstra, A., Francke, A. L., Bensing, J. M., \& van de Wiel, H. B. (2000). Evaluation of communication training programs in nursing care: A review of the literature. Patient Education and Counseling, 39(1), 129-145. https://doi.org/10.1016/s0738-3991(99)00096-8

Lamb, P. S., Mare, D. Q., \& Doecke, E. (2017). Key skills for the 21st century: An evidence-based review. Centre for International Research on Educational Systems.

Laschinger, H. K. S., Almost, J., Purdy, N., \& Kim, J. (2004). Predictors of nurse managers' health in Canadian restructured healthcare settings. Nursing Leadership (Toronto, Ont.), 17(4), 88-105.

Li, Y. W. (2016). Transforming conventional teaching classroom to learner-centred teaching classroom using multimedia-mediated learning module. International Journal of Information and Education Technology, 6(2), 105-112. https://doi.org/10.7763/IJIET.2016.V6.667

Li, Y., Cao, F., Cao, D., \& Liu, J. (2015). Nursing students' post-traumatic growth, emotional intelligence and psychological resilience. Journal of Psychiatric and Mental Health Nursing, 22(5), 326-332. https://doi.org/10.1111/jpm.12192

Lohman, D. F. (1996). Spatial ability and g. In I. Dennis \& P. Tapsfield (Eds.), Human abilities: Their nature and measurement (pp. 97-116). Lawrence Erlbaum Associates, Inc.

Maloney, M. E., \& Moore, P. (2019). From aggressive to assertive. International Journal of Women 's Dermatology, 6(1), 46-49. https://doi.org/10.1016/j.ijwd.2019.09.006

Marita, P., Leena, L., \& Tarja, K. (1999). Nurses' self-reflection via videotaping to improve communication skills in health counseling. Patient Education and Counseling, 36(1), 3-11. https://doi.org/10.1016/s0738-3991(98)00069-x 
Marran, A. L., Lima, P. G., \& Bagnato, M. H. S. (2015). As políticas educacionais e o estágio curricular supervisionado no curso de graduação em enfermagem. Trabalho, Educação e Saúde, 13(1), 89-108. https://doi.org/10.1590/1981-7746-sip00025

McCabe, C., \& Timmins, F. (2003). Teaching assertiveness to undergraduate nursing students. Nurse Education in Practice, 3(1), 30-42. https://doi.org/10.1016/S1471-5953(02)00079-3

Meuter, R. F. I., Gallois, C., Segalowitz, N. S., Ryder, A. G., \& Hocking, J. (2015). Overcoming language barriers in healthcare: A protocol for investigating safe and effective communication when patients or clinicians use a second language. BMC Health Services Research, 15, Article No. 371. https://doi.org/10.1186/s12913-015-1024-8

Montes-Berges, B., \& Augusto, J.-M. (2007). Exploring the relationship between perceived emotional intelligence, coping, social support and mental health in nursing students. Journal of Psychiatric and Mental Health Nursing, 14(2), 163-171. https://doi.org/10.1111/j.1365-2850.2007.01059.x

Morin, K. H. (2012). Evolving global education standards for nurses and midwives https://doi.org/10.1097/NMC.0b013e31825df7e7

Mukhtar, K., Javed, K., Arooj, M., \& Sethi, A. (2020). Advantages, Limitations and Recommendations for online learning during COVID-19 pandemic era. Pakistan Journal of Medical Sciences, 36(COVID19-S4), S27-S31. https://doi.org/10.12669/pjms.36.COVID19-S4.2785

Nakamura, Y., Yoshinaga, N., Tanoue, H., Kato, S., Nakamura, S., Aoishi, K., \& Shiraishi, Y. (2017). Development and evaluation of a modified brief assertiveness training for nurses in the workplace: A single-group feasibility study. BMC Nursing, 16, Article No. 29. https://doi.org/10.1186/s12912-017-0224-4

Nightingale, S., Spiby, H., Sheen, K., \& Slade, P. (2018). The impact of emotional intelligence in health care professionals on caring behaviour towards patients in clinical and long-term care settings: Findings from an integrative review. International Journal of Nursing Studies, 80, 106-117. https://doi.org/10.1016/j.ijnurstu.2018.01.006

Noro, L. R. A., Farias-Santos, B. C. de S., Sette-de-Souza, P. H., Cruz, R. K. S., Pinheiro, I. A. G., Borges, R. E. A., Nunes, L. M. F., \& Silva, S. M. (2015). O professor (ainda) no centro do processo ensino-aprendizagem em Odontologia. Revista da ABENO, 15(1), 2-11. https://doi.org/10.30979/rev.abeno.v15i1.146

Nursing and midwifery. (n. d.). World Health Organization. Retrieved May 20, 2019, from http://www.who.int/topics/nursing/en/

Omura, M., Maguire, J., Levett-Jones, T., \& Stone, T. E. (2016). Effectiveness of assertive communication training programs for health professionals and students: A systematic review protocol. JBI Database of Systematic Reviews and Implementation Reports, 14(10), 64-71. https://doi.org/10.11124/JBISRIR-2016-003158

Ouyang, Y.-Q., Zhou, W.-B., \& Qu, H. (2015). The impact of psychological empowerment and organisational commitment on Chinese nurses' job satisfaction. Contemporary Nurse, 50(1), 80-91. https://doi.org/10.1080/10376178.2015.1010253 
Oyeleye, O., Hanson, P., O’Connor, N., \& Dunn, D. (2013). Relationship of workplace incivility, stress, and burnout on nurses' turnover intentions and psychological empowerment: JONA: The Journal of Nursing Administration, 43(10), 536-542. https://doi.org/10.1097/NNA.0b013e3182a3e8c9

Parvari, A., Strider, D. B. A. S., Burchell, J., \& Ready, J. (2017). Selection and promotion of nursing leaders based on multiple intelligences. Human Resource Management Research, 7(1), 1-16.

Pearson, A., Jordan, Z., \& Munn, Z. (2012). Translational science and evidence-based healthcare: A clarification and reconceptualization of how knowledge is generated and used in healthcare. Nursing Research and Practice, 2012, Article No. 792519. https://doi.org/10.1155/2012/792519

Petrides, K., \& Furnham,A. (2000). On the dimensional structure of emotional intelligence. Personality and Individual Difference, 29(2), 313-320. https://doi.org/10.1016/S0191-8869(99)00195-6

Phaneuf, M. (2006). Multiple intelligences, a theory that can be applied to nursing. Retrieved from PrendreSoin.

Poroch, D., \& McIntosh, W. (1995). Barriers to assertive skills in nurses. The Australian and New Zealand Journal of Mental Health Nursing, 4(3), 113-123.

Rameez, A. (2019). English language proficiency and employability of university students: A sociological study of undergraduates at the Faculty of Arts and Culture, South Eastern University of Sri Lanka (SEUSL). International Journal of English Linguistics, 9, 199. https://doi.org/10.5539/ijel.v9n2p199

Rasheed, S. P., Younas, A., \& Sundus, A. (2019). Self-awareness in nursing: A scoping review. Journal of Clinical Nursing, 28(5-6), 762-774. https://doi.org/10.1111/jocn.14708

Rochester, S., Kilstoff, K., \& Scott, G. (2005). Learning from success: Improving undergraduate education through understanding the capabilities of successful nurse graduates. Nurse Education Today, 25(3), 181-188. https://doi.org/10.1016/j.nedt.2004.12.002

Rodrigues, C. C. F. M., Carvalho, D. P. de S. R. P., Salvador, P. T. C. de O., Medeiros, S. M. de, Menezes, R. M. de P., Ferreira Júnior, M. A., \& Pereira, V. E. (2016). Innovative nursing education from the perspective of epistemologies of the South. Escola Anna Nery - Revista de Enfermagem, 20(2). https://doi.org/10.5935/1414-8145.20160053

Ryan, D., Markowski, K., Ura, D., \& Liu-Chiang, C.-Y. (1998). International nursing education: Challenges and strategies for success. Journal of Professional Nursing, 14(2), 69-77. https://doi.org/10.1016/S8755-7223(98)80033-1

Samarakoon, L., Fernando, T., Rodrigo, C., \& Rajapakse, S. (2013). Learning styles and approaches to learning among medical undergraduates and postgraduates. BMC Medical Education, 13, Article No. 42. https://doi.org/10.1186/1472-6920-13-42

Sheahan, L., While, A., \& Bloomfield, J. (2015). An exploratory trial exploring the use of a multiple intelligences teaching approach (MITA) for teaching clinical skills to first year undergraduate nursing students. Nurse Education Today, 35(12), 1148-1154.

https://doi.org/10.1016/j.nedt.2015.05.002 
Spreitzer, G. M. (1995). Psychological empowerment in the workplace: Dimensions, measurement, and validation. Academy of Management Journal, 38(5), 1442-1465. https://doi.org/10.2307/256865

Squires, A., \& Jacobs, E. (2016). Language and communication issues impact healthcare providers around the world. International Journal of Nursing Studies, 54, 5-6. https://doi.org/10.1016/j.ijnurstu.2015.12.002

Sternberg, R. J. (2012). Intelligence. Dialogues in Clinical Neuroscience, 14(1), 19-27.

Stevens, K. R. (2013). The impact of evidence-based practice in nursing and the next big ideas. Online Journal of Issues in Nursing, 18(2), 4.

Sumskas, L., Czabanowska, K., Bruneviciūte, R., Kregzdyte, R., Krikstaponyte, Z., \& Ziomkiewicz, A. (2010). Specialist English as a foreign language for European public health: Evaluation of competencies and needs among Polish and Lithuanian students. Medicina (Kaunas, Lithuania), $46(1), 51-60$.

Taghavi Larijani, T., Mardani Hmouleh, M., Rezaei, N., Ghadiriyan, F., \& Rashidi, A. (2014). Relationship between assertiveness and critical thinking in nursing students. Journal of Nursing Education, 3(1), 32-40.

Thimbleby, H. (2013). Technology and the future of healthcare. Journal of Public Health Research, 2(3), e28. https://doi.org/10.4081/jphr.2013.e28

Thiruchelvi, A., \& Supriya, M. V. (2009). Emotional intelligence and job satisfaction. Asia Pacific Business Review, 5(2), 109-115. https://doi.org/10.1177/097324700900500209

Timmins, F., \& McCabe, C. (2004). How assertive are nurses in the workplace? A preliminary pilot study. Journal of Nursing Management, 13(1), 61-67.

https://doi.org/10.1111/j.1365-2834.2004.00492.x

Wang, V. C. X., \& Torrisi-Steele, G. (2015). Online teaching, change, and critical theory. New Horizons in Adult Education and Human Resource Development, 27(3), 18-26. https://doi.org/10.1002/nha3.20108

World Health Organization. (n.d.). Constitution. Retrieved May 20, 2019, from https://www.who.int/about/who-we-are/constitution

World Health Organization. (2018). Compendium of health system responses to large-scale migration in the WHO European Region.pdf. WHO Europe.

http://www.euro.who.int/_data/assets/pdf_file/0003/392205/Compendium_Health-System_ WHO_web_03.pdf?ua=1

Zamanzadeh, V., Jasemi, M., Valizadeh, L., Keogh, B., \& Taleghani, F. (2015). Effective factors in providing holistic care: A qualitative study. Indian Journal of Palliative Care, 21(2), 214-224. https://doi.org/10.4103/0973-1075.156506 